\title{
MARRIAGE REVERSE ANNUITY CONTRACT AND REVERSE MORTGAGE - APPLICATION OF A GENERALIZED MODEL OF REVERSIONARY ANNUITY
}

\author{
AGNIESZKA MARCINIUK \\ Wroclaw University of Economics, Faculty of Management, Computer Science and Finance, \\ Department of Statistics, Komandorska 118/120, 53-345 Wrocław, Poland \\ email: agnieszka.marciniuk@ue.wroc.pl
}

\begin{abstract}
The purpose of the paper is applying the generalized model of reversionary annuity to determine the benefit of marriage reverse annuity contracts and reverse mortgages. First of all, benefits depend on the age of spouses, their future lifetime and the real value of their properties which, in turn, determines the place where they live. In addition, the frequency of payments affects the amount of benefit. Therefore, the periodic benefits are determined for some regions of Poland on the basis of real Polish data from 2015, which mostly comes from The Central Statistical Office of Poland. Calculations of annuities are based on the fixed interest rate and the interest rate function depending on time $t$ for Polish real data. The results are later compared.
\end{abstract}

Key words: reverse annuity contract, reverse mortgage, reversionary annuity

JEL Codes: C41, C60, G17, G22, G120, J1, J080

DOI: 10.15611/amse.2017.20.24

\section{Introduction}

Societies lives longer and significant decrease in mortality force is observed for people at the retirement age. Social insurance pensions are low and may be insufficient to survive with dignity. In this context, an important issue is the possibility of obtaining additional financial resources. These solutions might be a reverse annuity contract and a reverse mortgage (cf. Davidoff 2009, Shao, at all. 2015, Shan 2011). Both spouses often own a real estate and can surrender their apartment to a company interested in the acquisition of such a property, in exchange for whole life or term annuity (cf. Debicka, Marciniuk 2014).

To determine the amount of reverse annuity contract, we distinguished a special case of a marriage joint life and reversionary annuity (cf. Luciano, at all., 2016), which pays yearly 1 financial unit as long as both members are alive and a fraction $R$ of it ( $R$ means a reduction factor, $R \in[0,1]$ ) when only one member of the couple is alive. The purpose of the paper is applying the generalized model of reversionary annuity to determine the benefit of marriage reverse annuity contracts and also to generalize the results for the reverse mortgages. Moreover, a case that the benefits can be paid more frequently the once a year is considered.

The benefits depend on the age of the spouses, their future lifetime and the real value of their properties which, in turn determines the place where they live. Therefore, the aim of this paper is to calculate the annuities for some regions of Poland on the basis of real Polish data from 2015, which follow mostly from The Central Statistical Office of Poland. These calculations are based on the fixed interest rate and the interest rate function depending on time $t$ for Polish real data. Finally, the results are discussed and compared. 


\section{Reversionary annuity}

The reverse annuity contract and reverse mortgage are benefits which an owner can receive in exchange for surrender-ring his real estate to a company, i.e. mortgage fund, created especially for this purpose or to a financial institution. These products are different (cf. Dębicka, Marciniuk, 2014). In case of reverse annuity contract the owner is guaranteed the right to stay in the property until his death by a notarial act. In the second case a financial institution takes over the property after the owner's death.

In this paper we concentrate on a marriage reverse annuity contract and a marriage reverse mortgage, which are variations of individual reverse annuity contract. However, we also distinguish other indirect cases. Under these contracts, annuity benefits are payable when both spouses are alive and sometimes after the death of whichever spouse. Thus we distinguish between two types of such contracts: a Joint-Life Status contract, when the benefit is paid only until the death of the first spouse and a Last Surviving Status contract by which the benefit is paid until the death of the other spouse.

The benefits of both contracts depend on the age of the spouses, their future lifetime and the real value of their properties. Therefore, we introduced some notations.

Let $m$ mean the number of sub-periods of year $(m>0)$ and $(x, y)$ be ages of entry of $x$ year-old husband and $y$-year-old wife. Let $K_{x}^{(m)}$ and $K_{y}^{(m)}$ be the future lifetimes of $x$-yearold man and $y$-year-old woman, which is determined in sub-periods of a year. $K_{x}^{(m)} \in\left\{0,1, \ldots, 0, m \cdot \omega_{x}\right\}$ and $K_{y}^{(m)} \in\left\{0,1, \ldots, 0, m \cdot \omega_{x}\right\}$, where $\omega_{x}$ (resp. $\omega_{y}$ ) denotes the difference between the age limit $\omega$ of the man (resp. woman) and man's (resp. woman's) age at entry $x$ (resp. $y$ ). The benefit of reverse annuity contract is paid for the whole life, and reverse mortgage is paid only for $n$-years. Note that according to Life Tables the age limit $\omega=100$ years (sometimes $\omega=110$ ). This implies that the maximum possible duration of the marriage reverse annuity contract is equal to $\max \left\{\omega_{x}, \omega_{y}\right\}$.

The value of real estate is denoted by $W$. Only percentage $\alpha$ (usually $\alpha \in(0 \%, 50 \%]$, cf. Dębicka, Marciniuk, 2014) of real estate $W$ is paid to the owners. Using the equivalent principal the benefit $b$ is determined from the following equation

$$
E(\alpha \cdot W)=E(b \cdot Z)
$$

where $Z$ means the discounted value of benefits.

Thus

$$
b=\frac{\alpha \cdot W}{E(Z)} \text {. }
$$

Now it is necessary to know the $E(Z)$. For this purpose the actuarial value of responsible life annuity and the probability of spouses surviving in the appropriate status are needed. Thus, two status and probability are determined below.

A Joint-Life Status (JLS) is defined as follows (cf. Bowers, et. al., 1986):

$$
u:=x: y \text {. }
$$

A future lifetime of this status is denoted by

$$
K_{u}^{(m)}=\min \left(K_{x}^{(m)}, K_{y}^{(m)}\right) .
$$

The probability that status $u$ will be surviving for at least $k$ sub-periods of a year is calculated by the following formula:

$$
{ }_{k / m} p_{u}={ }_{k / m} p_{x: y}=P\left(\frac{K_{u}^{(m)}}{m} \geq \frac{k}{m}\right)=P\left(\frac{K_{x}^{(m)}}{m} \geq \frac{k}{m}, \frac{K_{y}^{(m)}}{m} \geq \frac{k}{m}\right),
$$


where $k \in\left\{0,1, \ldots, 0, m \cdot \omega_{x}\right\}$ or $k \in\left\{0,1, \ldots, 0, m \cdot \omega_{y}\right\}$.

A Last Surviving Status (LSS) is denoted and defined by the use of $w$, i.e. (cf. Bowers, et. al., 1986):

$$
w:=\overline{x: y} .
$$

A future lifetime of status $w$ corresponds to $K_{w}$ and is defined as a maximum of $K_{x}^{(m)}$ and $K_{y}^{(m)}$, i.e.

$$
K_{w}^{(m)}=\max \left(K_{x}^{(m)}, K_{y}^{(m)}\right) .
$$

The probability that status $w$ will be surviving for at least $k$ sub-periods of a year is calculated by the use of ${ }_{k / m} p_{x: y}$ as follows

$$
\begin{aligned}
k{ }_{k m} p_{w}=P\left(K_{w}^{(m)} \geq k\right)=P\left(K_{x}^{(m)} \geq k \vee K_{y}^{(m)} \geq k\right)= \\
=P\left(K_{x}^{(m)} \geq k\right)+P\left(K_{y}^{(m)} \geq k\right)-P\left(K_{x}^{(m)} \geq k, K_{y}^{(m)} \geq k\right)= \\
={ }_{k / m} p_{x}+{ }_{k / m} p_{y}-{ }_{k / m} p_{x: y},
\end{aligned}
$$

where $k \in\left\{0,1, \ldots, 0, m \cdot \omega_{x}\right\}$ or $k \in\left\{0,1, \ldots, 0, m \cdot \omega_{y}\right\}$.

To determine a suitable annuity, we distinguished a special case of a marriage joint life and reversionary annuity (cf. Luciano, at all., 2016), which pays yearly 1 financial unit (or periodically $\frac{1}{m}$ financial unit, $m>0$ ) as long as both members are alive and a fraction $R$ of it ( $R$ means a reduction factor, $R \in[0,1]$ ) when only one member of the couple is alive. In this scheme, when $R=1$ means the Last Surviving Status (the benefit paid remains constant also after the first death), and the Joint-Life Status corresponds to $R=0$ (nothing is paid to the last survivor). We also consider other cases, when $R$ is different than 0 or 1

Yearly actuarial value of life annuity for spouses $(x, y)$, which is paid $\frac{1}{m}$ at the beginning of the sub-period of a year, is calculated as follows

$$
\begin{aligned}
a_{(x, y)}^{(m)} & =\frac{1}{m} \sum_{k=0}^{\infty} v^{\frac{k}{m}}\left[R\left({ }_{k / m} p_{x}-{ }_{k / m} p_{x: y}\right)+R\left({ }_{k / m} p_{y}-{ }_{k / m} p_{x: y}\right)+_{k / m} p_{x: y}\right]= \\
& =R a_{x}^{(m)}+R a_{y}^{(m)}+a_{x: y}^{(m)}(1-2 R),
\end{aligned}
$$

where $a_{x}^{(m)}$ is the actuarial value of the whole life annuity for a person aged $x$ and $a_{x: y}^{(m)}$ is the actuarial value of the whole life annuity for JLS, which pay $\frac{1}{m}$ at the beginning of a year (cf. Marciniuk 2016). In real, the maximum possible duration of the marriage reverse annuity contract is equal to $\max \left\{\omega_{x}, \omega_{y}\right\}$.

If $m=1$, formula (4) has the following form

$$
a_{(x, y)}=\sum_{t=0}^{\infty} v^{t}\left[R\left({ }_{t} p_{x}-{ }_{t} p_{x: y}\right)+R\left({ }_{t} p_{y}-{ }_{t} p_{x: y}\right)+{ }_{t} p_{x: y}\right]=R a_{x}+R a_{y}+a_{x: y}(1-2 R) .
$$

This special case is considered in Luciano, at all., 2016.

From (1) and (4), it is easy to show the following Lemma. 


\section{Lemma 1}

The yearly benefit of marriage reverse annuity contract for spouses $(x, y)$, which pays $\frac{1}{m}$ at the beginning of sub-period of a year as long as both members are alive and $\frac{R}{m}(m>0)$ when only one member of the couple is alive, is calculated as follows

$$
b_{(x, y)}^{(m)}=\frac{\alpha \cdot W}{R a_{x}^{(m)}+R a_{y}^{(m)}+a_{x: y}^{(m)}(1-2 R)}
$$

The Last Surviving Status is a special case when $R=1$ and the Joint-Life Status occurs when $R=0$.

This case could be generalized for marriage reverse mortgage in the following Lemma.

\section{Lemma 2}

The term yearly actuarial value of due life annuity for spouses $(x, y)$, which pays $\frac{1}{m}$ $(m>0)$ financial unit at the beginning of sub-period of a year as long as both members are alive and a fraction $R$ of it when only one member of the couple is alive, is calculated as follows

$$
\begin{aligned}
a_{(x, y): \bar{n} \mid}^{(m)} & =\frac{1}{m} \sum_{k=0}^{n \cdot m-1} v^{\frac{k}{m}}\left[R\left({ }_{k / m} p_{x}-{ }_{k / m} p_{x: y}\right)+R\left({ }_{k / m} p_{y}-{ }_{k / m} p_{x: y}\right)+{ }_{k / m} p_{x: y}\right] \\
& =R a_{x: \bar{n} \mid}^{(m)}+R a_{y: \bar{n} \mid}^{(m)}+a_{x: y: \bar{n} \mid}^{(m)}(1-2 R) .
\end{aligned}
$$

Hence, the due benefit of marriage reverse annuity contracts is determined by the following formula

$$
b_{(x, y): \bar{n} \mid}^{(m)}=\frac{\alpha \cdot W}{R a_{x: \bar{n} \mid}^{(m)}+R a_{y: \bar{n} \mid}^{(m)}+a_{x: y: \bar{n} \mid}^{(m)}(1-2 R)} .
$$

The Last Surviving Status is a special case when $R=1$ and the Joint-Life Status occurs when $R=0$.

Under the assumption that variables $K_{x}^{(m)}$ and $K_{y}^{(m)}$ are independent, the probability ${ }_{k / m} p_{x: y}$ is calculated as follows

Hence

$$
{ }_{k / m} p_{x: y}={ }_{k / m} p_{u}=P\left(K_{u}^{(m)} \geq k\right){ }_{k / m} p_{x} \cdot{ }_{k / m} p_{y} .
$$

$$
{ }_{k / m} p_{\overline{x: y}}={ }_{k / m} p_{w}={ }_{k / m} p_{x}+{ }_{k / m} p_{y}-{ }_{k / m} p_{x} \cdot{ }_{k / m} p_{y} .
$$

This special case is considered in this paper.

The probability ${ }_{k / m} p_{x}$ can be calculated by the use of the following formula (cf. Marciniuk 2009)

$$
{ }_{k / m} p_{x}={ }_{[k / m]} p_{x} \cdot{ }_{(k \div m)} p_{x+[k / m]},
$$

where $[a / b]$ means the integer part of a partition of $a$ and $b$, and $(a \div b)$ - the fractional part of a partition of $a$ and $b$. Under the assumption that the distribution of death within one year is uniform, the probability has following form (cf. Bowers, et al. 1986)

$$
{ }_{k / m} p_{x}=P\left(\frac{K_{x}^{(m)}}{m} \geq \frac{k}{m}\right)={ }_{[k / m]} p_{x} \cdot\left(1-(k \div m) \cdot\left(1-p_{x+[k / m]}\right)\right) \text {. }
$$




\section{Location analysis}

A real value of properties determines the place where people live. The analysis of benefit depending on a location is made based on some big cities in Poland.

To calculate the benefits, Wroclaw, Warsaw, Poznan, Gdansk, Lublin and Krakow were chosen. These cities are the capitals of large regions, for which The Life Tables from 2015 have been obtained. The data comes from The Central Statistical Office of Poland.

Table 1 presents the price (in Euro) per square meter of an apartment depending on its size and the average price per square meter of a house in selected Polish cities in December 2015.

Table 1: The average price of a square meter of a house in selected Polish cities in December 2015

\begin{tabular}{|c|c|c|c|}
\hline City & Size of apartment $\left(\mathrm{m}^{2}\right)$ & Primary market & Secondary market \\
\hline \multirow{4}{*}{ Gdansk } & $0-38$ & 1268 & 1519 \\
\hline & $38-60$ & 1240 & 1341 \\
\hline & $60-90$ & 1337 & 1322 \\
\hline & average & 1306 & 1354 \\
\hline \multirow{4}{*}{ Krakow } & $0-38$ & 1566 & 1611 \\
\hline & $38-60$ & 1469 & 1502 \\
\hline & $60-90$ & 1527 & 1497 \\
\hline & average & 1513 & 1548 \\
\hline \multirow{4}{*}{ Lublin } & $0-38$ & 1168 & 1200 \\
\hline & $38-60$ & 1126 & 1125 \\
\hline & $60-90$ & 1127 & 1066 \\
\hline & average & 1134 & 1103 \\
\hline \multirow{4}{*}{ Poznan } & $0-38$ & 1704 & 1358 \\
\hline & $38-60$ & 1457 & 1306 \\
\hline & $60-90$ & 1317 & 1217 \\
\hline & average & 1478 & 1281 \\
\hline \multirow{4}{*}{ Warsaw } & $0-38$ & 1829 & 1915 \\
\hline & $38-60$ & 1728 & 1791 \\
\hline & $60-90$ & 1742 & 1859 \\
\hline & average & 1811 & 1904 \\
\hline \multirow{4}{*}{ Wroclaw } & $0-38$ & 1524 & 1480 \\
\hline & $38-60$ & 1326 & 1301 \\
\hline & $60-90$ & 1340 & 1266 \\
\hline & se & 66 & 1300 \\
\hline
\end{tabular}

Source: own elaboration on the basis of http://www.bankier.pl/wiadomosc/Raport-z-rynku-mieszkan-styczen2016-7294818.html.

We can see that smaller houses are more expensive than the larger ones. The most expensive apartments are in Warsaw and the cheapest are in Lublin and in Gdansk. The prices are similar in Krakow and Poznan. In Wroclaw they are a little bit lower. The biggest differences between various sizes of an apartment are in Poznan. The real value of property is determined by the appraiser based on price lists from both primary and secondary market. Between these two prices there are no significant differences, but in the two cities of Warsaw and Poznan, these differences are greater. Therefore, the average price of the primary and secondary market is used for the calculations. 


\section{Rate of interest}

The discounting factor $v^{k}$ for $k=1,2, \ldots, n$ is given by the use of function $R_{0, k}$. The parameters of function $R_{0, k}$ are estimated by the use of the least-squares method on the basis of real Polish market data, related to the yield to maturity on zero-coupon and fixed interest bonds from 03.03.2015 (source: http://bossa.pl/notowania/stopy/rentownosc obligacji/). The estimation was made by the use of the Solver in Microsoft Excel (cf. Marciniuk 2009). Three models of spot interest rate, i.e. Svensson model (sv), Nelson-Siegel model (ns) and Bliss model (bl) are applied (cf. De Rezende, Ferreira 2013). In Figure 1, the data and all functions of interest rate models are presented.

Figure1. The model of spot interest rate.

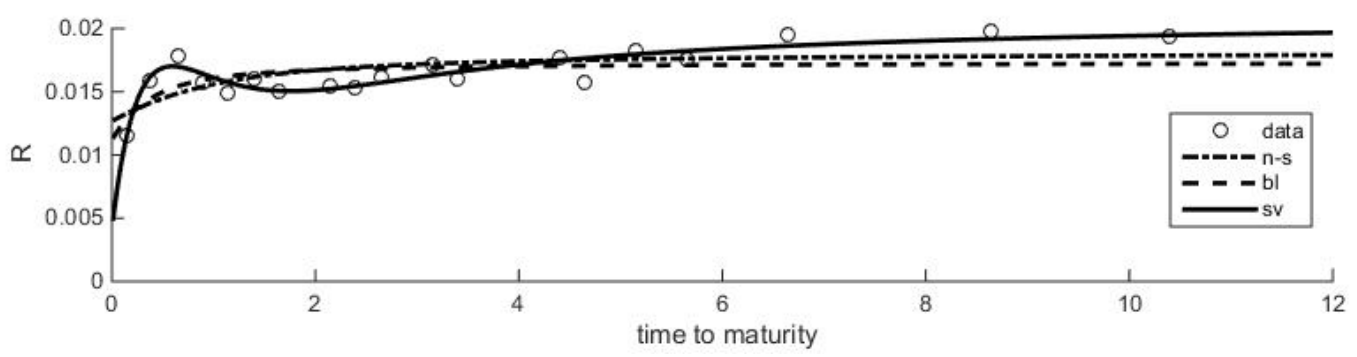

Source: Own elaboration.

The best fitted model is Svensson model, which can be seen in Figure 1. Therefore, this model is used to calculate the benefits. In this case function $R_{0, k}$ has the following form (cf. Marciniuk 2009)

$$
R_{0, k}=\beta_{0}+\beta_{1} \frac{\tau_{1}}{k}\left(1-e^{-\frac{k}{\tau_{1}}}\right)+\beta_{2}\left(\frac{\tau_{1}}{k}\left(1-e^{-\frac{k}{\tau_{1}}}\right)-e^{-\frac{k}{\tau_{1}}}\right)+\beta_{3}\left(\frac{\tau_{2}}{k}\left(1-e^{-\frac{k}{\tau_{2}}}\right)-e^{-\frac{k}{\tau_{2}}}\right),
$$

where

$\beta_{0}=0.02096, \quad \beta_{1}=-0.01684, \quad \beta_{2}=0.05844, \quad \beta_{3}=-0.05069, \tau_{1}=0.33388, \tau_{2}=0.57974$.

The parameter $\beta_{0}$ is the long term rate. To compare the results the constant interest rate $i=\beta_{0}=2.096 \%$ is also used to calculate the benefits.

\section{Benefits of marriage reverse annuity and marriage reverse mortgage}

In this section the results of numerical calculations on Polish real data are presented. All calculations are made by the use of own programs written in MATLAB.

First, the yearly benefits of marriage annuity contract (for $m=1$ ) are presented in Table 2 for a married couple, when husband is aged $x$ and $y$-year old wife, where $x, y \in\{60,70\}$. It is assumed that the marriage has a hundred square meter apartment. Its real value depends on the spouses' place of residence (cf. Table 1). The place of residence also influences the amount of benefit, because people's future lifetime differs in various voivodships. The Life Tables for seven chosen voivodships from 2015 are used. Moreover, the various fractions of $R$ are applied, where $R \in\left\{0,0.25, \frac{1}{3}, 0.5, \frac{2}{3}, 0.75,1\right\}$. If $R=0$, it means the Joint-Life Status. When $R=1$, we have the Last Surviving Status. Two cases are distinguished, i.e. the constant 
interest rate $i=2.096 \%$ ( $i$ - in Table 2) and the spot rate is given by the use of formula (10) (Sv-in Table 2). It is assumed that $\alpha=50 \%$.

Table 2. The benefit of marriage reverse annuity contract for different $\mathrm{R}$.

\begin{tabular}{|c|c|c|c|c|c|c|c|c|c|c|c|}
\hline$R$ & & & & & Krakow & & & la & $\mathrm{k}$ & $\mathrm{Poz}$ & \\
\hline & $i$ & $S v$ & $i$ & $S v$ & $S v$ & $i$ & $S v$ & $i$ & $S v$ & $i$ & $S v$ \\
\hline \multicolumn{12}{|c|}{$x=60, y=60$} \\
\hline 0 & 22 & $\longdiv { 6 5 }$ & 66 & 6788 & 55645501 & 4166 & 19 & 67 & 4911 & 228 & 516 \\
\hline 0.25 & & 03 & 03 & 35 & 934838 & 3640 & & & 94 & & 12 \\
\hline $1 / 3$ & 68 & 4220 & 762 & 5697 & 47044651 & 3493 & 3454 & 168 & 4121 & 4378 & 432 \\
\hline 0.5 & 9 & 3895 & 33 & 5273 & 674318 & 3232 & 96 & & 3815 & 49 & 4003 \\
\hline $2 / 3$ & 57 & 516 & 63 & 4908 & 0754029 & 3008 & 2974 & 91 & 3550 & 3766 & 372 \\
\hline 0.75 & & 1 & 97 & 47 & $43 \quad 3898$ & 2907 & 74 & & & 38 & 597 \\
\hline 1 & 00 & 64 & 59 & 11 & 5943553 & 2641 & 2611 & 154 & 118 & 3304 & 326 \\
\hline \multicolumn{12}{|c|}{$x=70, y=60$} \\
\hline 0 & 84 & 11 & 2 & 8645 & 72277147 & 5427 & 5366 & 438 & 6366 & 6787 & 671 \\
\hline 0.25 & & 78 & 50 & 30 & 59135847 & 4394 & 45 & 241 & 5182 & 10 & 44 \\
\hline $1 / 3$ & 021 & 4964 & 6753 & 6678 & 55755513 & 4131 & 4085 & 4935 & 4880 & 5185 & 512 \\
\hline 0.5 & 4488 & 37 & 6063 & 5995 & 50034947 & 3691 & 3650 & 419 & 4370 & 538 & 458 \\
\hline $2 / 3$ & 57 & 4012 & 02 & 5440 & 45384487 & 3335 & 3298 & 4001 & 3956 & 4195 & 414 \\
\hline 0.75 & 2 & 28 & 58 & 5199 & 43364287 & 3182 & 3146 & 3820 & 77 & 4004 & 395 \\
\hline 1 & 04 & 366 & 41 & 4589 & 38263783 & 2796 & 2765 & 364 & 3326 & 3522 & 348 \\
\hline \multicolumn{12}{|c|}{$x=60, y=70$} \\
\hline 0 & 85 & 16 & 64 & 71 & 7306654 & 5007 & 951 & 975 & 5909 & 6339 & 626 \\
\hline 0.25 & 00 & 41 & 12 & 7032 & 58195754 & 4326 & 4277 & 5145 & 5087 & 5442 & 538 \\
\hline $1 / 3$ & 5059 & 5002 & 6796 & 6719 & 55685505 & 4138 & 4091 & 4917 & 4862 & 5197 & 513 \\
\hline 0.5 & 4637 & 4585 & 6242 & 6171 & 51265068 & 3807 & 3764 & 4517 & 4466 & 4768 & 471 \\
\hline $2 / 3$ & 4280 & $42 J 1$ & 5771 & 5706 & 47494695 & 3526 & 3486 & 4177 & 4130 & 4404 & 435 \\
\hline 0.75 & 4121 & 4074 & 5561 & 5498 & 45804528 & 3400 & 3361 & 4026 & 3980 & 4242 & 4194 \\
\hline 1 & 3709 & 3666 & 5015 & 4958 & 41394092 & 3071 & 3036 & 3631 & 3590 & 3820 & 377 \\
\hline
\end{tabular}

The highest benefit is in Warsaw, due to the most expensive price per square meter apartment. Adequately, the smallest benefit is in Lublin. The differences between annuities, calculated by the use of constant interest rate $i=2.096 \%$ and Svennson model of spot rate $(S v)$ are not significant and amount to about $1.13 \%$. If $R<0.5$, the husband's age has a higher impact on the benefit. If $R \geq 0.5$, then the wife's age has a higher impact on the benefit. If the man is older, the benefit is higher. As the fraction $R$ increases, the amount of annuity decreases. These differences are from $40 \%$ to almost $50 \%$ when $R=1$ in relation to $R=0$. This can be seen in Figure 2, which presents the reverse annuity contract for Warsaw's marriages, when both spouses are at the same age $x=y \in\{60,61, \ldots, 99\}$.

The differences between benefits depending on $R$ increase with the age of spouses.

The marriage reverse mortgage is withdrawn only for $n$ years $n \leq 15$. Figure 3 presents the ten-year reverse mortgage for marriage from Warsaw depending on $R$. The benefit is higher than that of reverse annuity contract, but it is received for a shorter period of time.

In Figure 4 and 5 we can see the amount of benefit of marriage reverse for all voivodships when married couples are at the same age. On the first graph $R=0$, and on the second $R=1$. 
The legend means: Wroclaw - dol, Warsaw - maz, Krakow - mal, Lublin - lub, Gdansk pom, Poznan - wielk.

Figure 2. Reverse annuity contract for Warsaw married couple at the same age $x$.

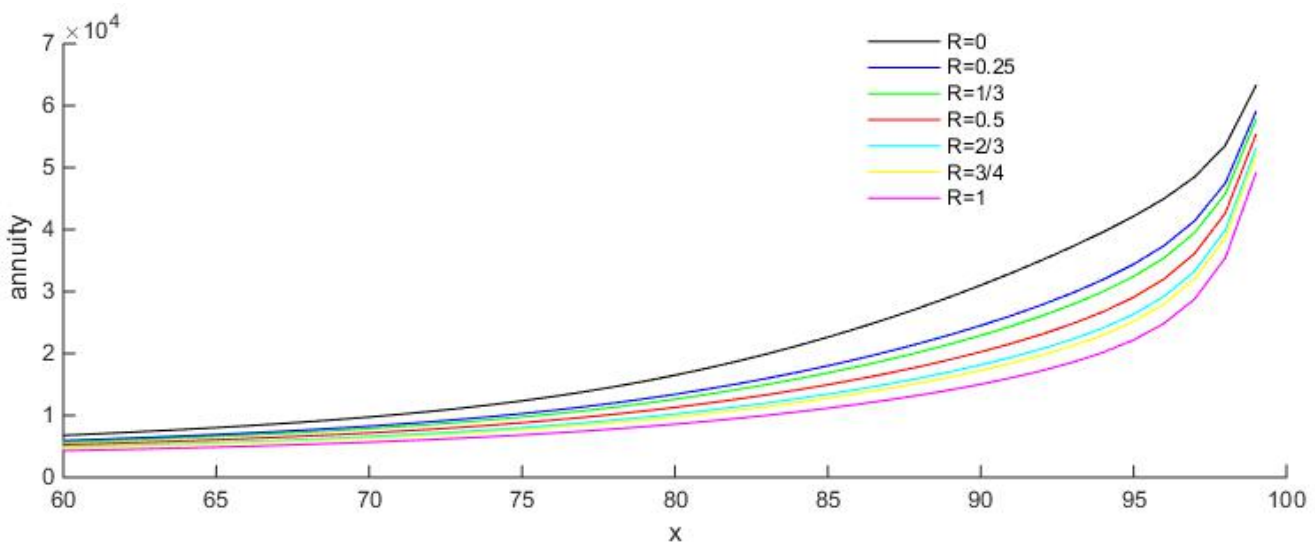

Source: own elaboration

Figure 3. The ten-year reverse mortgage for people from Warsaw.

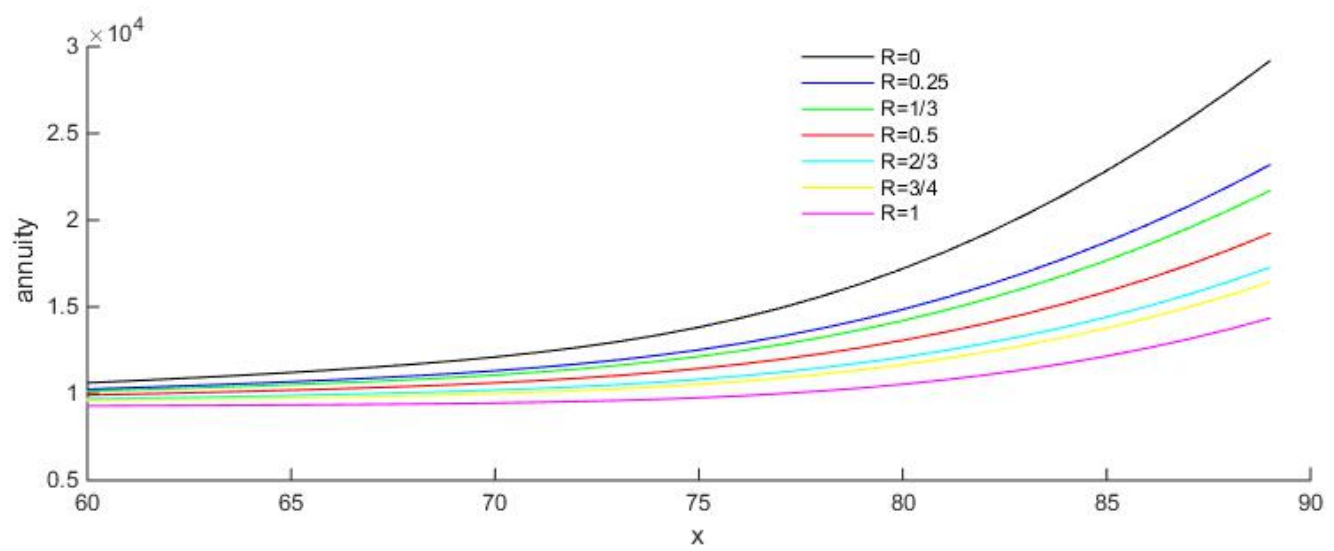

Source: own elaboration.

Figure 4. The ten-year marriage reverse mortgage for $R=0$.

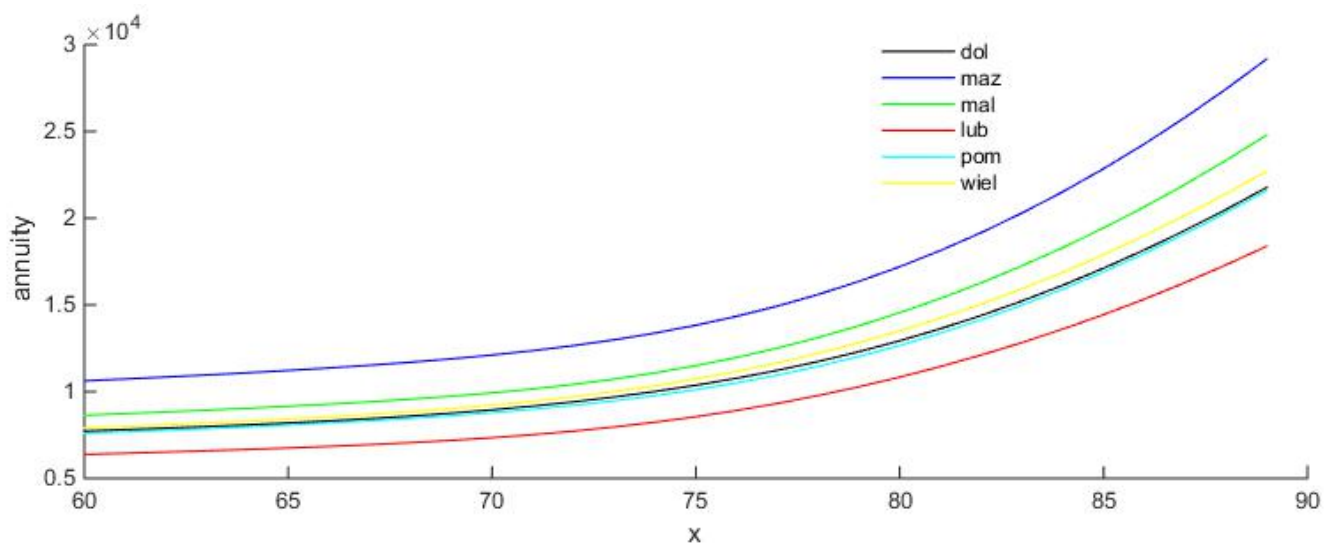

Source: own elaboration.

As before, it can be seen that for lower $R$ the benefit is higher. The benefit is the highest for marriages from Warsaw, and the lowest for those coming from Lublin. Analizying The 
Life Tables, one can notice that people live longer in the Malopolskie Voivodship. In Mazowieckie Voivodship, there are more older men and women than in other voivodships, which is reflected in the amount of benefits.

Let us assume that in each selected city the real value of the apartment is the same, i.e. $W=100000$ euros. The results are shown in Figure 6 for $R=0$.

Figure 5. The ten-year marriage reverse mortgage for $R=1$.

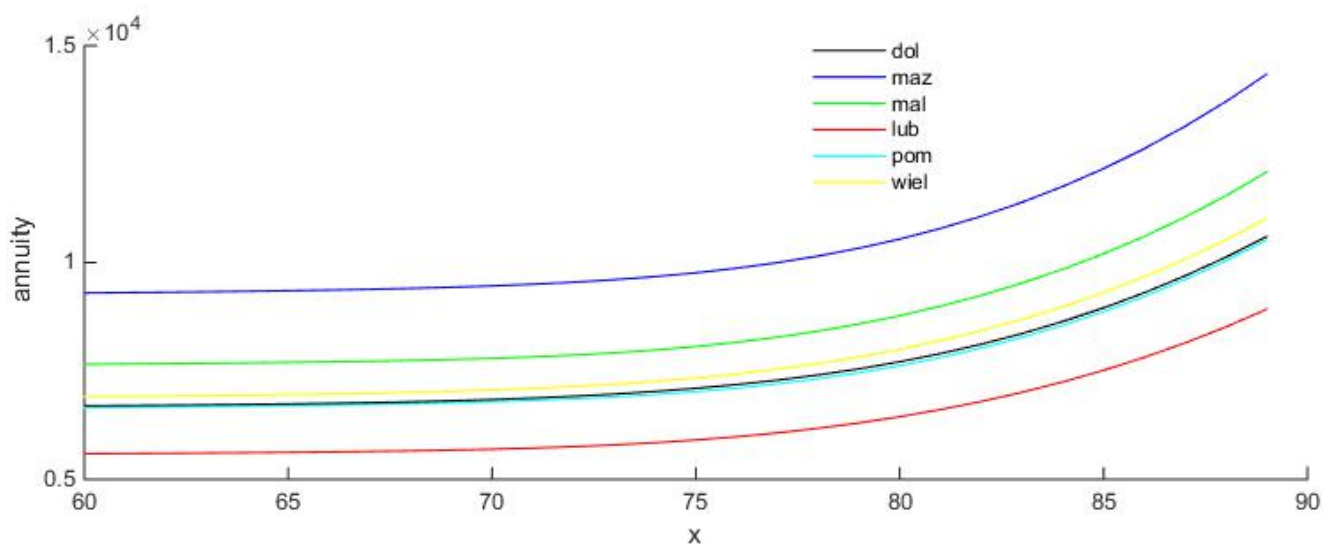

Source: own elaboration.

Figure 6. The ten-year marriage reverse mortgage for $R=0$ and $W=100000$ euro.

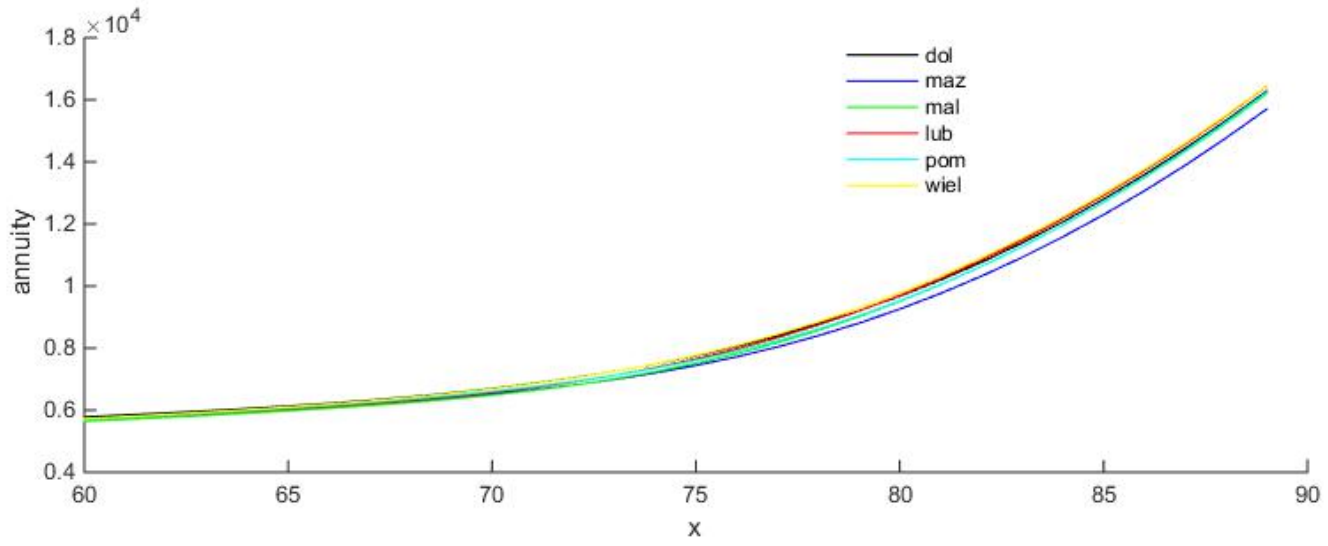

Source: own elaboration.

It is not difficult to notice, that the results are different. On the contrary, the lowest benefit is paid to older people in Mazowieckie Voivodship (i.e. in Warsaw). In other cases, the amount of annuity is similar.

\section{Conclusion}

In the paper the model of reversionary annuity has been applied and generalized for two marriage contracts, i.e. reverse annuity contract and reverse mortgage with payments more frequently than once a year. The amount of annuity depends very much on the spouses' place of residence. It is related to different lengths of future lifetime and even more with the price of a square meter apartment, which is shown in numerical calculations.

All calculations was made for the real Polish data from 2015 by the use of own interfaces written in MATLAB. Two models of interest rate are applied, i.e. constant interest rate and Svensson model of spot interest rate. It is assumed that a fixed interest rate is equal to the 
long-term rate of the Svensson model. The differences in the amounts of benefits are not significant. The benefits depends on the fraction $R$. As the fraction $R$ increases, the amount of annuity decreases. Furthermore, the calculations show a greater impact of a husband's age on the amount of benefit. If the man is older, the benefit is higher.

The calculation of benefits is made for married couples under the assumption that their future lifetimes are independent random variables. However this model might also be applied in case when future lifetime of spouses is dependent.

\section{Acknowledgements}

The support of the grant scheme NON-STANDARD MULTILIFE INSURANCE PRODUCTS WITH DEPENDENCE BETWEEN INSURED 2013/09/B/HS4/00490 is gladly acknowledged.

\section{References}

[1] Bowers, N. L., Gerber, H. U., Hickman, J. C., Jones, D. A., Nesbit, C. J. 1986. Actuarial Mathematics. Itasca, Illinois: The Society of Actuaries. ISBN 978-09-3895-946-5.

[2] Davidoff, T. 2009. Housing, Health, and Annuities. Journal of Risk and Insurance, 2009, vol. 76, iss. 1, pp. 31-52.

[3] De Rezende, R. B., Ferreira, M. S. 2013. Modeling and Forecasting the Yield Curve by an Extended Nelson-Siegel Class of Models: a quantile autorgression approach. Journal of Forecasting, 2013, vol. 32, iss. 2, pp. 111-123.

[4] Dębicka, J., Marciniuk, A. 2014. Comparision of reverse annuity contract and reverse mortgage on the Polish market. 17-th AMSE. Applications of Mathematics in Economics. International Scientific Conference: Poland, 27-31 August, 2014. Conference Proceedings. Wrocław: Wroclaw University Press, 2014, pp. 55-64. ISBN 978-83-7695-421-9.

[5] Luciano, E., Spreeuw, J., Vigna E. 2016 Spouses' Dependence across Generations and Pricing Impact on Reversionary Annuities. Risks, vol. 4 (2), pp. 1-18.

[6] Marciniuk, A. 2009. Nielosowe modele natychmiastowej stopy procentowej i ich zastosowanie w klasycznych ubezpieczeniach życiowych, Ekonometria 27, PN Wrocław University of Economics 84, Wrocław University of Economics Press, 2009, pp. 112-127.

[7] Marciniuk, A. 2016. Małżeńska renta hipoteczna uwzględniająca zależność między przyszłym czasem trwania życia małżonków. Studia Ekonomiczne, Zeszyty Naukowe UE w Katowicach nr 297, UE Katowice Press, pp. 114 - 132, ISSN 2083-8611.

[8] Shao, A. W., Hanewald, K., Sherris, M. 2015, Reverse mortgage pricing and risk analysis allowing for idiosyncratic house price. Insurance: Mathematic and Economics, 63 (2015), p. 76-90.

[9] Shan H. 2011. Reversing the Trend: The Recent Expantion of the Reverse Mortgage Market. Real Estate Economic, 2011, vol. 39, iss. 4, pp. 743-768. 